\title{
Contratos de locação imobiliária na pandemia
}

\author{
Real estate lease contracts in the pandemic
}

\section{Anderson Schreiber*}

\section{Resumo}

\begin{abstract}
O presente estudo examina os possíveis efeitos da pandemia do novo coronavírus sobre os diferentes tipos de contrato de locação imobiliária. Para tanto, parte das peculiaridades das relações locatícias residenciais e não residenciais, bem como das locações em shopping center. Conclui-se que, na maior parte dos casos, não se estará diante de impossibilidade da prestação, nem de excessiva onerosidade, como têm defendido diversos autores, mas sim da figura denominada "frustração do fim do contrato". Destaca-se, ainda, que essa frustração será, no mais das vezes, meramente temporária, o que recomenda não a extinção do vínculo obrigacional, mas sim a revisão do contrato. Ao final, aponta-se a utilidade do reconhecimento de um dever de renegociar tais contratos com base na cláusula geral de boa-fé objetiva e outros fundamentos. Para a realização da pesquisa, foi adotado o método dedutivo de investigação científica, com base na doutrina e na jurisprudência pertinentes à matéria.
\end{abstract}

Palavras-chave: Contrato de locação imobiliária. Impossibilidade da prestação. Onerosidade excessiva. Frustração parcial do fim do contrato.

\section{Abstract}

This study examines the potential effects of the covid-19 pandemic on different types of real estate lease contracts. For this purpose, residential and commercial lease agreements, as well as lease on shopping center, are examined in light of its main differences. This study concludes that, in most cases, the effect of the covid-19 pandemic in these contracts will not be the impossibility of performance nor hardship, but the situation known as "frustration of contractual purpose". It is also emphasized that this frustration, in most cases, will only be temporary, which recommends not the termination of the contract, but its revision. This study also points out the importance of the duty to renegotiate these contracts, based on the general clause of objective good faith and other legal grounds. For the development of the research, the author has adopted the deductive method of scientific investigation, based on doctrine and case law relevant to the matter.

Keywords: Real estate lease contracts. Impossibility of performance. Hardship. Temporary frustration of contractual purpose.

\section{Introdução}

Muito se tem dito sobre o impacto da pandemia nos contratos de locação imobiliária. Aí, como em qualquer outra relação contratual, deve-se privilegiar, ao máximo, o dever de renegociar. São os próprios contratantes que, melhor que ninguém, conhecem a realidade específica de sua relação contratual e os verdadeiros impactos que sofrem, estando mais preparados que qualquer um (inclusive, o magistrado) para readequar os termos de seus contratos à nova realidade, da forma que entenderem ser a melhor para ambos. Em alguns casos, contudo, a renegociação privada não tem chegado a bom termo e demandas têm sido propostas perante o Poder Judiciário com vistas à revisão, à suspensão ou ao diferimento do aluguel em virtude da pandemia, com algum apoio em artigos que vêm sendo publicados sobre o tema. Invoca-se ora o caso fortuito ou de força maior, ora o acontecimento extraordinário e imprevisível que justificaria a revisão - incorrendo no já denunciado equívoco de classificar fatos em tese, em vez de partir do impacto sofrido em cada relação contratual. Mesmo, contudo,

\footnotetext{
* Doutor em Direito Privado Comparado pela Università degli studi del Molise (Itália). Mestre em Direito Civil pela Universidade do Estado do Rio de Janeiro (UERJ). Professor Titular de Direito Civil da Universidade do Estado do Rio de Janeiro. Professor Permanente dos Programas de Mestrado e Doutorado em Direito Civil da Universidade do Estado do Rio de Janeiro. Membro da Academia Internacional de Direito Comparado. Procurador do Estado do Rio de Janeiro. Advogado. Rio de Janeiro - RJ - Brasil. E-mail: schreiber@schreiber.adv.br.
} 
quando se analisa o contrato em si, essas decisões judiciais e artigos doutrinários têm recorrido a institutos como a impossibilidade (total ou parcial) da prestação ou, ainda, ao desequilíbrio contratual superveniente (excessiva onerosidade) que a pandemia teria provocado sobre os contratos de locação. Trata-se, a nosso ver, de um erro que merece urgente correção de rota, a fim de se buscar solução tecnicamente sustentável à luz da ordem jurídica brasileira, diferenciando, ademais, o joio do trigo.

Inicia-se pela análise do tema no âmbito das locações de imóveis para fins residenciais, examinando, em seguida, as locações de imóveis para fins não residenciais (especialmente comerciais), sendo diferenciada, ainda, a situação da locação em shopping center. Por fim, abordam-se, em um último item, os limites da atuação do Poder Judiciário nessa matéria e a importância da renegociação no âmbito das locações.

\section{Locações residenciais}

O contrato de locação residencial não sofre, em regra, nenhum efeito em virtude da pandemia. Não há que se falar em impossibilidade das prestações: ceder o uso e gozo do imóvel para fins residenciais continua sendo possível (jurídica e materialmente), assim como continua sendo possível, no mesmo sentido, pagar aluguel. A possibilidade da prestação é, como se sabe, aferida em abstrato. Evidentemente, o locatário pode experimentar, em virtude da pandemia, dificuldade para pagar o aluguel, por força de fatores externos ao contrato de locação, como a suspensão do seu contrato de trabalho, a sua demissão ou, de modo mais geral, a redução de sua receita. O dentista, por exemplo, que deixa de atender pacientes durante a pandemia e sofre drástica redução de seus ganhos pode viver dificuldades para pagar o aluguel, chegando até a ruína. Essas dificuldades não configuram, tecnicamente, impossibilidade da prestação que Ihe compete (pagamento do aluguel) e nem mesmo desequilíbrio do contrato de locação. As dificuldades subjetivas (pessoais) do locatário não se qualificam como excessiva onerosidade para fins de revisão do contrato de locação. Com efeito,

a aferição do desequilíbrio contratual superveniente deve, assim, restar exclusivamente centrada sobre aspectos objetivos, vinculados ao objeto do contrato, independentemente de encontrarem ou não razão mediata ou imediata em características subjetivas dos contratantes (SCHREIBER, 2018, p. 213).

As dificuldades econômicas que locatários residenciais vêm experimentando por conta da pandemia podem, a depender de sua amplitude e intensidade, sensibilizar o Congresso Nacional para que, por meio de intervenção legislativa, imponha um desconto no valor dos aluguéis ou o diferimento de parte do seu pagamento para um momento futuro, quando passada a pandemia e retomado o curso normal da economia. Era o que constava, a título ilustrativo, no artigo 10 do Projeto de Lei $n .^{0} 1.179 .{ }^{1} \mathrm{O}$ artigo em questão foi, todavia, suprimido no Senado Federal, não tendo ingressado na redação final da Lei n. ${ }^{\circ}$ 14.010/2020.

Tal proposta, como se extrai do próprio texto (que aludia à "demissão, redução de carga horária ou diminuição de remuneração" $)^{2}$ não se fundava nem em impossibilidade da prestação, nem em desequilíbrio contratual - que exigiria, por definição, análise do contrato específico -, mas em uma aspiração de desafogo para os locatários residenciais em geral diante das dificuldades econômicas provocadas pela pandemia. Trata-se de medida polêmica, pois, ao conceder desconto ou diferimento a um locatário, implica impor, em igual medida, sacrifício a um locador, que pode, por exemplo, depender do recebimento dos aluguéis para sua própria subsistência.

Independentemente da opinião de cada um a esse respeito, é certo que não se trata de solucionar um problema afeto ao contrato de locação em si, mas sim às dificuldades pessoais do locatário. A pandemia, ou

\footnotetext{
"Art. 10. Os locatários residenciais que sofrerem alteração econômico-financeira, decorrente de demissão, redução de carga horária ou diminuição de remuneração, poderão suspender, total ou parcialmente, o pagamento dos alugueres vencíveis a partir de 20 de março de 2020 até 30 de outubro de 2020 . $\S 1^{\circ} \mathrm{Na}$ hipótese de exercício da suspensão do pagamento de que trata o caput, os alugueres vencidos deverão ser pagos parceladamente, a partir de 30 de outubro de 2020, na data do vencimento, somando-se à prestação dos alugueres vincendos o percentual mensal de $20 \%$ dos alugueres vencidos. $\S 2^{\circ}$ Os locatários deverão comunicar aos locadores o exercício da suspensão previsto no caput. $\S 3^{\circ} \mathrm{A}$ comunicação prevista no $\S 2^{\circ}$ poderá ser realizada por qualquer ato que possa ser objeto de prova lícita."

2 Referência que é, de certo modo, atécnica, como já se registrou: "Aliás, deveria ser integralmente suprimida a referência a 'redução de carga horária' que, por si só, não é exemplo de alteração econômico-financeira." (SCHREIBER; MANSUR, 2020).
} 
melhor, as medidas governamentais e particulares adotadas para combater a pandemia não provocam nem impossibilidade, nem desequilíbrio do contrato de locação residencial, nem afetam substancialmente a sua fruição.

Ao contrário, o contrato de locação residencial, em muitos casos, tem sido mais fruído do que nunca. As medidas governamentais adotadas para evitar a circulação de pessoas, bem como as próprias recomendações das entidades nacionais e internacionais engajadas na proteção da saúde, fizeram com que mais e mais pessoas ficassem em casa e a hashtag \#fiqueemcasa tornou-se - com a adesão, registre-se, do autor - uma das mais populares na internet. Nesse cenário, locatários residenciais passam a fruir mais da prestação do que era esperado originariamente, porque confinados, mas isso não dá direito ao locador de exigir incremento no aluguel - do mesmíssimo modo que, conforme se verá adiante, a redução da fruição do imóvel pelo locatário comercial não lhe dá, só por isso, direito ao desconto.

O que pode se verificar na locação residencial que recaia sobre imóvel em condomínio edilício é, como tem se visto em alguns casos, a imposição de restrições ao uso de áreas comuns, como playground, academia ou piscina. Tal restrição de fruição não parece, a princípio, suficiente a impor redução do valor do aluguel, pois o uso da unidade autônoma que atende à finalidade essencial do contrato (fim residencial, de moradia) permanece assegurado, sendo objeto de até maior fruição, conforme já se destacou. Tais restrições, ademais, não são impostas pelo proprietário do imóvel, mas decorrem, em geral, das decisões da assembleia ou, excepcionalmente, do síndico, adotadas no sentido de preservar a saúde e a vida de todos os moradores. $O$ mesmo se pode dizer em relação à proibição, que tem se verificado em alguns casos, de visitação externa, cumprindo destacar que todas essas medidas restritivas devem necessariamente ser objeto, ainda que a posteriori, do debate no âmbito interno do condomínio, cabendo ao síndico usar dos meios eletrônicos disponíveis para conclamar reuniões por videoconferência ou conferência telefônica, com ampla notícia a todos os moradores. ${ }^{3}$ Referidas medidas sujeitam-se, ademais, ao controle judicial, seja quanto à sua necessidade, seja quanto à sua adequada delimitação no âmbito da própria vida condominial.

Também pode ser que o valor dos imóveis como um todo venha a cair em virtude da pandemia ou, mais particularmente, em virtude do período de recessão econômica que se seguirá, segundo a maior parte das análises e projeções, e que já se faz sentir em alguma medida. De modo geral, porém, os imóveis continuam, hoje, a ser anunciados e ofertados pelo mesmo valor, talvez porque muitas pessoas acreditem que o impacto é meramente temporário. Amanhã, pode ser que os valores dos imóveis caiam substancialmente, o que pode gerar, aí sim, desequilíbrio contratual superveniente, no âmbito do qual se adentrará a interessante discussão sobre se é cabível ou não uma ação de revisão do valor da prestação (aluguel) antes do prazo de três anos, previsto na Lei do Inquilinato (art. 19). ${ }^{4}$ Há doutrina em ambos os sentidos, ${ }^{5}$ embora a melhor posição seja de que a ação de revisão é cabível mesmo antes dos três anos.

Passa-se, agora, a examinar a locação para fins não residenciais, popularmente denominada "locação comercial".

\section{Locação comercial}

Em relação à locação comercial, numerosos autores têm sustentado que há impossibilidade (total ou parcial) da prestação. Na visão desses autores, as medidas governamentais que impedem o exercício de

\footnotetext{
Registre-se que a Lei n. 14.010/2020, ao instituir o Regime Jurídico Emergencial e Transitório das relações jurídicas de Direito Privado (RJET) no período da pandemia do novo coronavírus (Covid-19), passou a admitir, excepcionalmente, a realização de assembleias condominiais por meios virtuais: "Art. 12. A assembleia condominial, inclusive para os fins dos arts. 1.349 e 1.350 do Código Civil, e a respectiva votação poderão ocorrer, em caráter emergencial, até 30 de outubro de 2020, por meios virtuais, caso em que a manifestação de vontade de cada condômino será equiparada, para todos os efeitos jurídicos, à sua assinatura presencial."

4 "Art. 19. Não havendo acordo, o locador ou locatário, após três anos de vigência do contrato ou do acordo anteriormente realizado, poderão pedir revisão judicial do aluguel, a fim de ajustá-lo ao preço de mercado."

Em sentido favorável à possibilidade de revisão antes do prazo trienal, registre-se a opinião de Luiz Fux: "Em resumo, a dissociação do aluguel de seu preço de mercado, elevado a patamares além do razoável por força da indexação do aluguel arbitrado judicialmente, resulta em onerosidade excessiva em detrimento do locatário, exigindo a pronta intervenção judicial quer por força da aplicação da teoria da imprevisão quer por força do princípio que veda a lesão superveniente nos contratos, e autorizando a propositura da ação revisional do aluguel do contrato antes do triênio do art. 19 da Lei n. 8.245/91, ou a ação a que se refere o art. 471 do CPC, em face da natureza sucessiva das prestações locatícias" (FUX, 1993). Em sentido contrário: "A prefixação de um prazo para que as partes se socorram da revisional, ainda que discutível, tem por objetivo evitar que a relação contratual se tumultue, com sucessivas ações, separadas por curtos intervalos, o que geraria uma grande insegurança, que não se coaduna com o princípio da estabilidade dos contratos" (SOUZA, 2012, p. 330).
} 
diferentes setores do comércio implicariam a impossibilidade da prestação do locador, consubstanciada na cessão do uso e gozo do imóvel comercial. Sustentam, nessa direção, que tais medidas representariam "fato do príncipe" e que a própria pandemia exprimiria "caso fortuito ou de força maior" que resulta na impossibilidade da prestação. ${ }^{6}$

Sob o prisma técnico-jurídico, não se vislumbra, contudo, a impossibilidade da prestação do contrato de locação não residencial por força da pandemia. Recorde-se que a impossibilidade consiste na falta de possibilidade jurídica ou material da prestação em si:

\begin{abstract}
Esta possibilidade é abstrata, aferida em tese, mas não se limita ao ponto de vista material, abrangendo também o jurídico. A possibilidade material consiste no fato de a prestação ser fisicamente alcançável. É nula, segundo os clássicos exemplos da manualística, a obrigação de 'tocar o céu' ou de 'entregar a outrem um centauro', porque tais prestações são materialmente impossíveis. Também são nulas as obrigações cujo objeto consista em prestação juridicamente impossível, vale dizer, vedada por lei. (TEPEDINO; SCHREIBER, 2020, p. 10).
\end{abstract}

As normas que impedem o exercício de certas atividades comerciais podem afetar duramente o locatário de imóvel comercial, mas não resultam em impossibilidade da prestação do locador, que consiste, também aqui, na cessão do uso e gozo do imóvel. Tal prestação segue plenamente possível sob o prisma material e jurídico. O locatário continua tendo a posse direta do imóvel, continua dotado do exercício das faculdades de uso e gozo do imóvel. Basta, por exemplo, verificar que os bens móveis do locatário continuam no imóvel, o que não deixa de caracterizar o exercício do uso do imóvel, ao contrário do locador, que não pode usá-lo. Na mesma direção:

[...] o locatário não perdeu a posse direta do imóvel. Seus bens (mercadorias, móveis etc.) se encontram no imóvel locado. O locador não pode 'entrar' no imóvel sob pena de esbulho possessório, o locador prossegue privado do uso da coisa. Não, a prestação do locador está sendo prestada continuamente. (SIMÃO, 2020).

As restrições governamentais ao exercício do comércio podem tornar impossível o exercício de determinada atividade que o locatário pode ter decidido desenvolver naquele imóvel, mas isso não integra a prestação em si. O que pode ocorrer, nesses casos, é uma frustração do fim ao qual a prestação se dirige, hipótese que examinaremos mais adiante, mas não há impossibilidade da prestação do locador. O locador, em regra, não participa dos riscos do ramo comercial que o locatário decide explorar, incluindo o risco de que o exercício daquela atividade comercial venha a ser inteiramente proibida pelo Poder Público, como ocorre, por exemplo, quando uma nova lei proíbe a comercialização de armas, de amianto ou de qualquer produto por se mostrar nocivo à saúde. Esses não são casos de impossibilidade da prestação do locador.

Pelas mesmas razões, não se verifica uma impossibilidade parcial ou temporária da prestação do locador. A impossibilidade parcial ou temporária pressupõe impossibilidade em alguma medida ou por certo tempo. O problema aqui, repete-se, não é de impossibilidade das prestações do contrato: o uso e gozo do imóvel continuam transferidos continuamente ao locatário (o locador não retomou o imóvel). Também não há impossibilidade da prestação do locatário comercial, consubstanciada no pagamento do aluguel, que continua sendo plenamente possível sob o prisma jurídico e material. Aliás, sendo o aluguel fixado usualmente em dinheiro, a prestação do locatário é, por natureza, daquelas que dificilmente se impossibilitariam. Não há, portanto, impossibilidade parcial ou temporária, como também não há deterioração da coisa ou da própria prestação. As prestações da locação comercial seguem hígidas. O seu fim é que é afetado, como se verá mais adiante.

\footnotetext{
"Por outro lado, em se tratando de locações comerciais de imóveis que tenham sua utilidade eliminada ou reduzida pelo fechamento do comércio, não se afigura necessário nem pertinente recorrer àqueles dispositivos em linha de partida. O fechamento do comércio, determinado pelo Estado, é hipótese de caso fortuito ou força maior - mais especificamente, o que os administrativistas designam fato do príncipe. (...) Disto decorre, no contexto do fechamento do comércio, que antes do locatário, é o locador que comete o inadimplemento; ele falha ao 'garantir' o cumprimento da função comercial do imóvel. Este inadimplemento é fruto da impossibilidade fática da prestação, resultante do caso fortuito ou força maior. Em tal hipótese, em que não vislumbra culpa do devedor, este não responde por perdas e danos (art. 393 do CC); o inadimplemento, todavia, é efeito da impossibilidade - o chamado inadimplemento fortuito - e perdura enquanto não for possível, ao locatário, usar o imóvel para a finalidade que Ihe atribui o contrato" (ANDRADE JR., 2020).
} 
Também não se trata de desequilíbrio contratual. Não há onerosidade excessiva no cumprimento da prestação em virtude de alteração do seu valor econômico. Com efeito,

[...] por desequilíbrio contratual superveniente deve-se compreender não apenas a hipótese em que há o agravamento do sacrifício econômico imposto ao contratante ao longo do tempo, mas também aquela em que tal sacrifício econômico torna-se desproporcional em relação ao benefício econômico derivado do contrato (SCHREIBER, 2018, p. 222).

Não há, hoje, notícia de desequilíbrio econômico entre a prestação do locador (cessão do uso e gozo do imóvel) e a prestação do locatário (aluguel) nas locações comerciais. Como já destacado em relação às locações residenciais, os imóveis atualmente continuam negociados por valores substancialmente idênticos, mas podem, em breve, se desvalorizar em virtude da recessão econômica que já começa a ser imposta pela pandemia. Aí sim, teríamos desequilíbrio contratual superveniente, atraindo a já noticiada discussão sobre o cabimento de ação de revisão do valor do aluguel antes do prazo de três anos previsto na lei especial (Lei do Inquilinato, art. 19). ${ }^{7}$ Hoje, contudo, não é o que acontece. O problema não está no valor econômico das prestações ou na correspondência econômica (equivalência material) entre elas, mas no fim do contrato de locação do imóvel comercial, que não pode ser alcançado pelo locatário por certo lapso de tempo.

Registre-se que, assim como na locação residencial, eventuais dificuldades que o locatário possa experimentar no cumprimento dessa prestação por força da redução de seus ganhos dizem respeito não à prestação em si, mas à sua própria economia. Evidentemente, sua capacidade financeira pode estar sendo afetada justamente pela frustração da receita que ele esperava aferir por meio da combinação de diversos fatores, entre os quais se inclui o uso e gozo do imóvel. Isso, contudo, não tornam impossíveis ou desequilibradas as prestações do contrato de locação comercial. Por exemplo, se uma loja vai mal e não vende porque os consumidores não a procuram naquele mês do ano, porque houve muitas chuvas (evento da natureza, como é, nesse sentido, a pandemia) e poucas pessoas saíram de casa (por decisão própria ou porque a Prefeitura recomendou que ficassem em suas casas), porque, em virtude de Olimpíadas em um país vizinho, todos viajaram, ou porque há uma recessão econômica derivada de alguma razão qualquer, esses são fatores que não afetam a possibilidade jurídica da prestação de pagar aluguel, nem dão ensejo ao desequilíbrio superveniente do contrato de locação se o valor do imóvel permanecer estável.

O problema aqui, em suma, não está nas prestações que seguem em equilíbrio e cujo cumprimento continua sendo possível. O problema está na frustração do fim do contrato.

O instituto da frustração do fim do contrato não foi disciplinado expressamente entre nós, mas tem sido retomado com intensidade nos últimos anos. Dissertações e teses valorosas têm sido escritas sobre o tema. Há muitos aspectos técnicos que poderíamos examinar, mas fiquemos no essencial. Frustração do fim do contrato é denominação tomada de empréstimo do direito inglês, que desenvolveu, a partir da sensibilidade de sua jurisprudência, a chamada doctrine of frustration. Vale relembrar o célebre caso Krell v. Henry: um grande cortejo fora organizado para os dias 26 e 27 de junho de 1902, a fim de celebrar a coroação do rei Eduardo VII, a primeira coroação britânica em mais de sessenta anos, havendo sido divulgado que o referido cortejo passaria pela Pall Mall, uma avenida de Londres que se situa a apenas alguns quarteirões do Palácio de Buckingham. Uma semana antes, Mister Krell, proprietário de um apartamento em Pall Mall, aluga a Mister Henry seu imóvel, com vista para a avenida, por um valor significativo. Alguns dias depois, o futuro Rei adoece, adiando-se indefinidamente a coroação. Mister Henry, não tendo mais interesse na locação, recusa-se a efetuar o pagamento do aluguel, o que leva Mister Krell a acioná-lo em juízo.

A corte inglesa responsável por julgar o caso entendeu que, embora não estivesse exatamente diante de uma hipótese de "impossibility" (impossibilidade) - já que o pagamento do aluguel pelo imóvel continuava se afigurando possível -, tratava-se de situação análoga à impossibilidade, por ter restado "frustrated" (frustrado) o "foundation of the contract" (fundamento do contrato), consubstanciado na passagem do cortejo real. ${ }^{8}$ Casos similares foram analisados em seguida, como Chandler v. Webster, ${ }^{9}$ formando um conjunto

Sobre os diferentes posicionamentos sobre o tema, confira-se a nota 5, supra.

Krell vs. Henry, 1903, 2 K.B. 740 (C.A.). Para comentários adicionais sobre o caso, ver, entre outros, MCELROY; WILLIAMS, 1941, p. 241-260).

Chandler v. Webster, 1904, 1 K.B. 493. 
de precedentes denominado sinteticamente "coronation cases" (casos da coroação), que está na base da doctrine of frustration, hoje aceita e aplicada também pela jurisprudência dos Estados Unidos da América e do Canadá (SCHWARTZ, 2010, p. 804).

A ideia de que um contrato pode deixar de ser vinculante pela frustração do seu fim converge com construções que já vinham sendo desenvolvidas, desde o fim do século XIX, na Alemanha, especialmente a partir da teoria da pressuposição apresentada por Windscheid de modo mais sistemático em 1850, na sua obra Die Lehre des römischen Rechts von der Voraussetzung,${ }^{10}$ bem como de aprimoramentos sucessivos, como a chamada teoria da base do negócio (Geschäftsgrundlage) de Paul Oertmann, publicada em 1921, a teoria da vontade eficaz de Erich Kaufmann (1911), a teoria da reserva virtual de Paul Krückmann (1918), os trabalhos vanguardistas (porque de caráter predominantemente objetivo) de Eugen Locher (1923), e, finalmente, a teoria mista da base do negócio de Karl Larenz, cuja genialidade está em uma combinação sistemática das construções subjetivistas (mais ligadas à ideia de fim contratual) com as construções objetivistas (mais ligadas à ideia de equilíbrio econômico entre as prestações) em uma única e abrangente teoria da base negocial. ${ }^{11}$

No direito brasileiro, vivemos uma fratura nessa temática. O problema gerado pelo desequilíbrio econômico das prestações foi enfrentado pelo legislador, que, embora com uma ou outra insuficiência, disciplinou o tema expressamente no Código Civil (arts. 478 a 480, 317, entre outros) e nas leis especiais (CDC, art. $6^{\circ}$, V; Lei do Inquilinato, art. 19). ${ }^{12}$ Já o problema da frustração do fim do contrato não encontra, todavia, previsão normativa no Brasil.

Alguns poucos autores tratam pontualmente da matéria (AZEVEDO, 2009, p. 41-62; COGO, 2012, passim) e alguns outros parecem se referir ao tema sob um rótulo demasiadamente abrangente de "quebra da base do negócio", expressão que é usada de modo bastante ambíguo no Brasil, seja porque há, na Alemanha, numerosas teorias da base do negócio, seja porque, entre nós, o legislador contempla expressamente o desequilíbrio econômico que integra a noção de alteração da base do negócio sob a perspectiva da excessiva onerosidade (seguindo a construção italiana), o que acaba por tornar a invocação de uma noção abrangente de base do negócio, tal como concebida por Larenz e disciplinada atualmente no BGB (§313), um fator de confusão adicional em nossa doutrina e jurisprudência. Daí por que se mostra preferível empregar a expressão "frustração do fim" ou, ainda, o termo "pressuposição" - como tem preferido a jurisprudência italiana (pressuposizione), por exemplo, ainda que sem reproduzir na íntegra a concepção de Windscheid -, a fim de contemplar especificamente uma questão que nosso direito positivo não aborda. Cingir-se a essas expressões, longe de uma discussão de mera terminologia, é um modo de perceber, com maior clareza, quando se pode identificar sua ocorrência e debater, com maior especificidade, qual a solução que poderia ser aplicada à luz da nossa ordem jurídica.

Voltando às locações comerciais afetadas por medidas restritivas impostas no combate à pandemia, verifica-se, em muitos casos, a frustração do fim do contrato. Pense-se, por exemplo, na locação de loja de rua em uma cidade como o Rio de Janeiro, em que o Decreto $n .^{\circ}$ 47.282/2020 determinou a "suspensão (...) do funcionamento dos estabelecimentos que pratiquem o comércio de bens, ressalvados os seguintes [listados], desde que garantido o espaçamento mínimo de dois metros entre os seus ocupantes". Não há impossibilidade da prestação, nem desequilíbrio contratual superveniente; o que há é a frustração do fim do contrato.

As restrições governamentais ao exercício do comércio podem tornar impossível o exercício de determinada atividade que o locatário pode ter decidido desenvolver naquele imóvel, mas isso não integra a

10 A construção de Windscheid é considerada pioneira por romper, em alguma medida, com as construções anteriores que, ao longo da primeira metade do século XIX, procuravam conduzir o tema do desequilíbrio contratual à teoria do erro (GALLO, 1992, p. 14).

11 Após analisar minuciosamente a jurisprudência alemã e as diversas teorias formuladas por seus conterrâneos, Larenz propõe uma dupla significação para a base do negócio: "em primeiro lugar, como a base 'subjetiva' da determinação da vontade de uma ou ambas as partes, como uma representação mental existente ao se concluir o negócio que tenha influenciado grandemente na formação dos motivos. Em segundo lugar, como a base 'objetiva do contrato (enquanto complexo de sentido inteligível), ou seja, como o conjunto de circunstâncias cuja existência ou persistência pressupõe devidamente o contrato - saibam ou não os contratantes -, já que, se assim não fosse, não se lograria o fim do contrato, o propósito das partes contratantes e a subsistência do contrato não teria 'fim, sentido ou objeto'” (LARENZ, 1956, p. 37, tradução livre).

12 Código de Defesa do Consumidor: "Art. $6^{\circ}$ São direitos básicos do consumidor: (...) V - a modificação das cláusulas contratuais que estabeleçam prestações desproporcionais ou sua revisão em razão de fatos supervenientes que as tornem excessivamente onerosas". Lei do Inquilinato: "Art. 19. Não havendo acordo, o locador ou locatário, após três anos de vigência do contrato ou do acordo anteriormente realizado, poderão pedir revisão judicial do aluguel, a fim de ajustá-lo ao preço de mercado." 
prestação em si. Isso consiste no fim para o qual as partes celebraram o contrato. Do mesmo modo, não se verifica desequilíbrio entre as prestações. Não há onerosidade excessiva no cumprimento da prestação em virtude de alteração do seu valor econômico: isso pode se verificar se, ao longo dos meses, o valor do imóvel se depreciar, em virtude (menos da pandemia em si e mais) da recessão econômica que promete ocorrer e já mostra seus primeiros sinais. O problema que deriva do fechamento do comércio por alguns meses não está, portanto, no valor econômico das prestações (cessão do uso e gozo do imóvel versus valor do aluguel) ou na correspondência econômica (equivalência material) entre tais prestações. O problema está no fim do contrato de locação do imóvel comercial, que o locatário não poderá alcançar por certo lapso de tempo.

Diante dessa constatação, faz-se necessário perguntar: qual a solução da ordem jurídica brasileira para esse problema? Qual o efeito, entre nós, da frustração do fim do contrato? Como dito, não há uma solução expressa em nosso direito positivo, mas a ampla maioria da doutrina defende que a frustração do fim suprime ipso jure a eficácia do contrato. Por conta disso, alguns autores têm sustentado que a hipótese é idêntica à impossibilidade, vista em chave funcional - solução que não é recomendável, seja porque confunde o fim da prestação com o fim do contrato, seja porque mistura a impossibilidade com um fenômeno diverso que é a frustração ou, como preferem os italianos, a irraggiungibilità ("inalcançabilidade", com o perdão dos amantes do vernáculo) do fim. ${ }^{13}$

Além disso, há todo o problema relacionado ao caráter comum do fim contratual: diferentemente do que ocorre na impossibilidade - que é um fato que afeta a prestação -, a frustração do fim atinge o objetivo perseguido pelas partes. A doutrina estrangeira destaca, de modo uníssono, que não basta a frustração de um fim unilateral, mantido em segredo ou, mais tecnicamente, em reserva mental. É preciso que, de algum modo, esse fim tenha sido compartilhado entre os contratantes. Esse problema, de elevada sofisticação, é estranho à disciplina da impossibilidade, porque o objeto da relação obrigacional (prestação) é sempre comum. $E$ isso conduz a uma derradeira diferença quanto aos efeitos: enquanto na impossibilidade sem culpa do devedor, o direito ordena a restituição ao status quo ante, sem indenização de quem quer que seja; o mesmo não se verifica, necessariamente, na frustração do fim, em que muitos autores defendem uma solução mais afeita ao compartilhamento de riscos, como ocorre na Inglaterra, em que o Law Reform (Frustrated Contracts) Act, de 1943, determina que

[...] se a parte a quem os valores foram pagos ou eram devidos incorreu em despesas antes do momento da extinção para, ou para o propósito de, cumprir o contrato, a corte poderá, se considerar justo fazê-lo diante de todas as circunstâncias do caso, autoriza-lo a reter ou, se for o caso, recuperar todo ou parte do montante pagou o devido, desde que tal montante não exceda as despesas incorridas. (MARINHO, 2020, p. 113)

Nesse sentido, a frustração do fim do contrato aproxima-se mais, sob a perspectiva remedial, do desequilíbrio que da impossibilidade.

No exemplo da locação de loja de rua, parece certo que as medidas de restrição adotadas no combate à Covid-19 atingem, em regra, não o fim unilateral do locatário, mas o fim comum do contrato. Com efeito, a finalidade da exploração econômica do imóvel integra a própria estrutura do contrato - quem loca um imóvel o loca para certo fim, porque a própria tipologia do contrato em nosso direito positivo estimula esse olhar finalístico ao diferenciar as locações residenciais das locações não residenciais (comerciais, industriais etc.). Ainda assim, pode-se argumentar que não necessariamente o fim específico foi definido no instrumento contratual. Frequentemente, porém, o é: contratos de locação para fins não residenciais usualmente estabelecem, por exemplo, que o comércio ou a indústria serão o fim da locação, e não raro especificam também qual ramo do comércio ou indústria será explorado, seja por meio de cláusula expressa, seja por força da própria qualificação do locatário, seja por meio dos documentos constitutivos cujo encaminhamento antecede, de hábito, a celebração do contrato de locação e definem o objeto social do contratante. A questão é, contudo, matéria de prova, que deve ser avaliada pelo julgador. É, todavia, comum, pelas razões já

\footnotetext{
“L'ordinamento nel quale l'irraggiungibilità dello scopo contrattuale assume maggiormente rilevanza è probabilmente quello italiano. In Italia, pur in mancanza di un qualsiasi riscontro normativo, e nonostante l'ostilità della dottrina specie meno recente, ha infatti trovato applicazione la teoria della presuposizione proposta da Windscheid" (GALLO, 1992, p. 297).
} 
expostas, que não se verifiquem no caso da locação algumas dificuldades de caráter teleológico que são inerentes ao instituto da frustração do fim, facilitando a vida do intérprete.

Por outro lado, o exemplo da locação apresenta uma dificuldade que se verifica em muitos outros contratos afetados pela pandemia: trata-se de um contrato de execução sucessiva, que, no dizer da doutrina, se renova mês a mês. ${ }^{14}$ Assim, a frustração do fim do contrato não terá sido total, integral ou definitiva, mas durará apenas certo lapso de tempo cujo encerramento se pode, desde já, antever. Quid juris? Há uma frustração temporária do fim do contrato? Se há, quais são os seus efeitos?

Se muito pouco foi escrito na doutrina brasileira sobre a frustração do fim do contrato, menos ainda foi dito sobre a frustração temporária ou parcial do fim do contrato. A própria formulação da doutrina da frustração talvez sugira a impossibilidade de seu reconhecimento: sendo o fim contratual um objetivo a ser perseguido de modo permanente, ou o fim se frustra ou ainda é alcançável. Todavia o exemplo dos contratos de execução continuada ou sucessiva (como a locação de imóvel para fins não residenciais) recomenda um olhar mais sensível à realidade prática. A situação, aliás, é corriqueira, independentemente da pandemia. O locatário da loja de rua fica ocasionalmente impossibilitado de exercer o comércio - por alguns dias, se chove torrencialmente na cidade; por alguns meses, se eclode uma pandemia que conduz o Poder Público a fechar o comércio; ou até por alguns anos, se, por hipótese, uma reforma urbana impede ou restringe substancialmente o acesso de pedestres a uma rua, como aconteceu no Rio de Janeiro por conta das obras relacionadas aos Jogos Olímpicos de 2016.

Em tais situações, nosso ordenamento jurídico não oferece uma resposta clara. É evidente que se a duração da restrição for excessivamente prolongada, pode ser que, a depender do prazo de vigência do contrato, o fim contratual reste inteiramente ou substancialmente frustrado. Pode ocorrer, todavia, o contrário: o número de dias ou meses pelos quais perdura a restrição ao comércio pode, à luz de todo o prazo de vigência do contrato, exprimir uma frustração meramente temporária ou parcial do fim contratual. O que fazer em tais casos? Parte da doutrina recomenda que se aplique, nessa hipótese, remédio análogo àquele reservado ao desequilíbrio contratual superveniente, em especial o direito à revisão do contrato. A analogia é mais que razoável, retomando a linha que sempre foi seguida nessa matéria nos países de tradição romano-germânica. Se, no passado, a abertura à revisão contratual era vista com desconfiança, hoje a experiência jurisprudencial revela que nossas cortes agem, em geral, com parcimônia, limitando-se às alterações imprescindíveis ao reequilíbrio econômico do contrato. ${ }^{15}$

É certo que a autocomposição entre as partes é, sempre, um caminho preferível. O incentivo da doutrina e da jurisprudência a essa autocomposição é relevante e pode ser alcançado, como se verá adiante, por meio do reconhecimento do dever de renegociar, que é, em apertada síntese, o dever de ingressar de boa-fé em uma tentativa de renegociação. Não alcançada, contudo, uma solução, restará ao locatário o caminho da ação de revisão do contrato, com base na frustração temporária do fim contratual.

\section{Ação de revisão do contrato de locação com base na frustração temporária do fim do contrato}

A ação de revisão do contrato com base na frustração temporária do fim do contrato não se confunde com a ação de revisão do contrato amparada no desequilíbrio entre as prestações. Assim, mesmo aqueles que defendem que a ação revisional do artigo 19 da Lei do Inquilinato exclui a incidência do remédio

14 "De execução sucessiva ou de trato sucessivo, ou execução continuada, como denominado no art. 478, é o contrato que sobrevive, com a persistência da obrigação, muito embora ocorram soluções periódicas, até que, pelo implemento de uma condição, ou decurso de um prazo, cessa o próprio contrato. O que a caracteriza é o fato de que os pagamentos não geram a extinção da obrigação, que renasce. A duração ou continuidade da obrigação não é simplesmente suportada pelo credor, mas é querida pelas partes contratantes. Caso típico é a locação, em que a prestação do aluguel não tem efeito liberatório, senão do débito correspondente a período determinado, decorrido ou por decorrer, porque o contrato continua até a ocorrência de uma causa extintiva" (PEREIRA, 2013, p. 62).

15 "De modo geral, pode-se afirmar que nossos tribunais continuam ainda extremamente apegados ao pacta sunt servanda e à reconstrução da vontade originária dos contratantes no novo cenário fático, de tal modo que tendem a rejeitar a revisão contratual. Quando há a revisão, os tribunais parecem cautelosos na sua aplicação, limitando-se a reajustes e readequações mínimas. Sempre será possível encontrar, sobretudo em primeira instância, onde é mais volumoso o número de decisões, um ou outro caso de excesso do magistrado, mas tal situação não é privativa do tema do desequilibrio contratual superveniente, em que as aberrações não são, definitivamente, a regra" (SCHREIBER, 2018, p. 272-273). 
revisional dos artigos 317 c/c 478 do Código Civil, devem admitir a ação de revisão com base na frustração temporária do fim do contrato, independentemente do decurso do lapso de três anos. Os fundamentos da revisão são distintos - o que reforça, aliás, a importância de tratar a frustração do fim do contrato como hipótese distinta do desequilíbrio, evitando a adoção do rótulo geral de "quebra da base do negócio", que mescla os dois institutos, o que, se não é prejudicial à luz do direito positivo de outros países que já os contemplam expressamente, assume consequências nocivas entre nós.

Na ação de revisão do contrato com base na frustração temporária do fim do contrato, o Poder Judiciário deve aferir se estão presentes os pressupostos necessários. Mais uma vez, é preciso notar que a situação não se confunde com o desequilíbrio contratual superveniente, que assenta sobre a desproporção econômica entre as prestações. Aqui, compete ao juiz aferir outras condições, especialmente: (a) se o fim do contrato (exploração do comércio) era um fim comum (vale dizer: o instrumento contratual ou outras circunstâncias permitiam assumir que o locador locou o imóvel para aquele fim); e (b) se o acontecimento superveniente comprometeu efetivamente a realização do fim contratual por certo tempo.

Em relação a esse último ponto, convém esclarecer que, tecnicamente, a frustração do fim somente se verifica naquelas cidades - e a realidade brasileira é vasta e diferenciada nesse aspecto - em que houve efetiva restrição ao comércio por medidas adotadas pelo Poder Público ou espontaneamente pela coletividade de consumidores. Mesmo nas cidades em que houve restrição, alguns ramos do comércio, como supermercados e farmácias, continuaram em funcionamento (em alguns casos, até com aumento de demanda). Assim, o locatário de um espaço comercial que explora uma dessas atividades não sofre, em regra, frustração do fim do contrato. Trata-se, em resumo, de matéria de prova. A frustração do fim do contrato não deve ser empregada como rótulo abstrato e genérico, cabendo ao locatário demonstrar em que medida a atividade comercial foi afetada no seu caso específico, inclusive mediante comprovação da queda absoluta ou significativa de suas receitas.

Comprovados os requisitos da frustração do fim comum do contrato, compete ao magistrado avaliar se a frustração foi integral ou parcial. A frustração integral implica supressão da eficácia do contrato. Já na frustração parcial, essa supressão é igualmente parcial, mantendo-se, em parte, as obrigações do contratante. Aqui, uma observação relevante: o fim de exploração do comércio abrange não apenas o recebimento do público e a realização das vendas, mas também outros aspectos, como o armazenamento de mercadorias, que podem seguir íntegros mesmo com o impedimento ao comércio em si. Tudo isso deve ser levado em consideração pelo magistrado, ao avaliar o impacto sofrido no contrato, a partir das provas produzidas pelo locatário.

O que não deve o julgador fazer é ingressar na economia particular do locador para avaliar seu faturamento, suas receitas gerais, sua margem de lucro etc. Tal solução, a nosso sentir, extrapola completamente o objeto da ação de revisão do contrato por diversas razões. Em primeiro lugar, porque o objeto da ação é estruturalmente limitado àquela relação contratual que se examina, não estando o julgador autorizado a analisar outros contratos mantidos pelas partes - os mecanismos que permitem a análise da economia geral das partes no direito brasileiro (recuperação de empresas, falência, insolvência civil) contam com garantias substanciais importantes, como o par conditio creditorum (igualdade entre credores), que restariam, inevitavelmente, violadas se os efeitos de outros contratos fossem utilizados como fundamento para decidir se um contrato específico deve ou não ser revisado.

Além disso, não parece haver dúvida de que o exercício da livre iniciativa e a fruição da propriedade privada são protegidos constitucionalmente (Constituição, arts. $1^{\circ}, \mathrm{IV} ; 5^{\circ}, \mathrm{XXII} ; 170$, caput e inciso II), de modo que o locador tem direito ao recebimento dos aluguéis no valor que estipulou, salvo alguma patologia juridicamente relevante que afete o contrato de locação. A medida da redução de ganhos do locador deve ser, portanto, a exata medida em que o contrato foi juridicamente afetado, sendo certo que nosso ordenamento não confere poderes ao juiz estatal ou ao árbitro para determinar a porção de rendimentos que considera "justa". Não há autorização do nosso ordenamento para julgamentos de equidade que imponham redução de ganhos a quem quer que seja sem amparo em institutos jurídicos.

Por fim, é de se notar que, nem mesmo sob uma ótica de equidade ou avaliação de justiça no caso concreto, seria correto analisar, em um dado momento temporal (pandemia), a existência de lucro e sua 
extensão, assim como o valor das receitas que determinada pessoa natural ou jurídica recebe em virtude da exploração de seus bens e do desenvolvimento de atividades econômicas. Não se sabe, por exemplo, se determinada pessoa amargou anos de prejuízos com a propriedade de um imóvel (ou com sua desvalorização patrimonial ao longo do tempo, a depender do preço de compra, da região, do comportamento do mercado) para, agora, estar auferindo lucro. Uma análise de justiça sobre lucros e receitas, ainda que fosse admitida pela ordem jurídica - o que não é -, não poderia, no plano filosófico, ser realizada sem consideração de toda a trajetória econômica do locador ou do locatário.

O único caminho para obter descontos ou reduções no recebimento de aluguel sem a identificação de uma patologia contratual juridicamente reconhecida seria uma intervenção legislativa nas relações locatícias. Convém recordar, todavia, que o Congresso Nacional rejeitou o já mencionado artigo 10 do Projeto de Lei $n .^{\circ} 1.179$, que autorizava a suspensão e o diferimento do pagamento de parte dos aluguéis para um momento futuro, quando passada a pandemia e retomado o curso normal da economia - norma, de todo modo, limitada às locações residenciais. ${ }^{16}$

Registre-se, por fim, que não se ignora a insegurança jurídica decorrente da aplicação judicial de um instituto cujos contornos não estejam previamente delimitados em lei. Tanto a enunciação dos requisitos exigidos quanto o rol de efeitos potencialmente produzidos podem encontrar alguma variação a depender da referência doutrinária consultada. Essas dificuldades, no entanto, não podem acarretar a recusa da prestação jurisdicional pleiteada, especialmente porque, apesar de divergências pontuais, a doutrina brasileira converge para a necessidade de se tutelar as hipóteses de frustração do fim contratual. Aqui, a segurança jurídica, compreendida não como absoluta previsibilidade do resultado final da ação, mas sim como uma razoável estabilidade na interpretação do instituto, apenas será alcançada por meio da avaliação crítica, por parte da academia, dos fundamentos das decisões judiciais nessa matéria - o que pressupõe, naturalmente, que as decisões não descartem a frustração do fim, de modo apriorístico, simplesmente em razão da ausência de previsão expressa em lei. A experiência brasileira no campo do desequilíbrio contratual superveniente pode, uma vez mais, servir de referência: apesar da teoria da imprevisão ser acolhida pelo Supremo Tribunal Federal desde $1938,{ }^{17}$ a introdução de uma regra geral sobre a matéria apenas se deu com o Código Civil de 2002, após mais de seis décadas de experiência jurisprudencial e a produção de diversas obras dedicadas ao tema (SCHREIBER, 2018, p. 158-161).

\section{Locação em shopping center}

A situação da locação em shopping center, embora peculiar em sua disciplina jurídica, ${ }^{18}$ assemelhase, no tocante à pandemia, aos efeitos já descritos para as locações não residenciais. Faz-se necessário, contudo, diferenciar duas hipóteses: (a) locação em shopping center fechado por determinação do Poder

16 “Art. 10. Os locatários residenciais que sofrerem alteração econômico-financeira, decorrente de demissão, redução de carga horária ou diminuição de remuneração, poderão suspender, total ou parcialmente, o pagamento dos alugueres vencíveis a partir de 20 de março de 2020 até 30 de outubro de 2020 . $\S 1^{\circ} \mathrm{Na}$ hipótese de exercício da suspensão do pagamento de que trata o caput, os alugueres vencidos deverão ser pagos parceladamente, a partir de 30 de outubro de 2020, na data do vencimento, somando-se à prestação dos alugueres vincendos o percentual mensal de $20 \%$ dos alugueres vencidos. $\S 2^{\circ}$ Os locatários deverão comunicar aos locadores o exercício da suspensão previsto no caput. $\S 3^{\circ} \mathrm{A}$ comunicação prevista no $\S 2^{\circ}$ poderá ser realizada por qualquer ato que possa ser objeto de prova lícita."

STF, Pleno, RE n. ${ }^{\circ}$ 2.675, Rel. Min. Laudo de Camargo, Rel. ad hoc Min. Costa Manso, j. 5.1.1938.

18 Lei do Inquilinato: "Art. 54. Nas relações entre lojistas e empreendedores de shopping center, prevalecerão as condições livremente pactuadas nos contratos de locação respectivos e as disposições procedimentais previstas nesta lei. $\S 1^{\circ} \mathrm{O}$ empreendedor não poderá cobrar do locatário em shopping center: a) as despesas referidas nas alíneas $a, b$ e $d$ do parágrafo único do art. 22; e b) as despesas com obras ou substituições de equipamentos, que impliquem modificar o projeto ou o memorial descritivo da data do habite - se e obras de paisagismo nas partes de uso comum. $\S 2^{\circ}$ As despesas cobradas do locatário devem ser previstas em orçamento, salvo casos de urgência ou força maior, devidamente demonstradas, podendo o locatário, a cada sessenta dias, por si ou entidade de classe exigir a comprovação das mesmas." Sobre esta modalidade especial de locação, v. considerações tecidas por Schreiber, 2020, p. 566-567. 
Público - como aconteceu, por exemplo, nas cidades do Rio de Janeiro, ${ }^{19}$ João Pessoa ${ }^{20}$ e Porto Alegre, ${ }^{21}$ entre tantas outras; (b) locação em shopping center que permaneceu aberto durante a pandemia, mas sofreu severo impacto com a diminuição da circulação de pessoas.

A prova da frustração temporária do fim contratual é, naturalmente, mais simples nos casos em que houve o fechamento do shopping center em que se situa o imóvel locado. Ainda que tal fechamento tenha decorrido de medida governamental inevitável pelo próprio locador, o fato é que o locatário terá se visto diante da frustração do fim do seu contrato. Repita-se: o caso não é de impossibilidade da prestação, pois a posse continua transferida ao locatário mesmo nesses casos, seus bens continuam lá e o próprio locatário pode dar outros usos ao imóvel (armazenamento etc.). Tampouco se trata de desequilíbrio econômico se o valor do aluguel continua a corresponder ao valor da cessão de uso e gozo de uma loja com aquelas características em um empreendimento como aquele em que se situa. A questão é de frustração do fim contratual.

Embora o fechamento do shopping center represente prova robusta, não se deve descartar a configuração da frustração do fim contratual mesmo nos casos em que o empreendimento permaneceu aberto. Naturalmente, alguma circulação de pessoas representa impacto menor no alcance do fim contratual que nenhuma circulação de pessoas, mas algum impacto a redução de circulação por prolongado período produz. Aqui, não há outro caminho que não examinar a situação concreta, recaindo o ônus probatório sobre locatário, que deverá demonstrar a redução substancial e consistente de suas receitas no lapso temporal em que alega a frustração do fim contratual.

Quanto ao caráter comum ou compartilhado do fim contratual, não parece haver dúvida de que a locação em shopping center atende a esse requisito, na medida em que a própria estrutura do contrato envolve a premissa comum de funcionamento e até de configuração interna do empreendimento (tenant mix), compartilhada de modo expresso entre os contratantes, no próprio instrumento contratual ou em instrumentos paralelos que disciplinam a relação entre o empreendedor e os lojistas. ${ }^{22}$

\section{6 À guisa de conclusão: dever de renegociar}

Afigura-se de suma importância identificar e delimitar tecnicamente os efeitos das patologias que podem se verificar, diante da pandemia, em relação a contratos de locação. Aludir genericamente a eventos de "caso fortuito", de "força maior" ou, ainda, a acontecimentos "extraordinários e imprevisíveis", lança a discussão em um debate abstrato e teórico sobre a classificação de acontecimentos, quando, tecnicamente, o que se deveria fazer é partir sempre do impacto sobre o contrato em si e da avaliação de sua relevância jurídica à luz dos institutos já consagrados no ordenamento ou daqueles que, porventura, possam ter sido adicionados por lei emergencial. O que não pode fazer o julgador é "sacar da cartola" soluções de equidade, que, conquanto possam estar inspiradas nas melhores intenções, são inerentemente injustas, na medida em que exprimem uma aplicação imprevisível e não isonômica de respostas casuísticas a problemas que atingem toda a sociedade. É preciso, portanto, estar atento ao fato de que, mesmo em caso de disputa judicial, o sistema jurídico funciona como limite dos remédios que o julgador pode aplicar aos problemas que surgem na relação contratual específica que se examina.

Além disso, parece de suma importância estimular os contratantes a obterem soluções consensuais diante de um período que, conquanto trágico, se promete temporário. Daí porque se faz necessário reconhecer

19 Em que o artigo $4^{\circ}, \mathrm{XIV}$, do Decreto Estadual RJ n. ${ }^{\circ} 46.980 / 2020$ determinou a suspensão temporária do "funcionamento de 'shopping center', centro comercial e estabelecimentos congêneres".

20 Artigo $3^{\circ}$, II, do Decreto Estadual PB n. ${ }^{\circ}$ 40.135/2020: "Art. $3^{\circ}$ Em caráter excepcional, em razão da necessidade de intensificar as medidas de restrição previstas no Decreto Estadual n 40.122, de 13 de março de 2020, que decretou Situação de Emergência no Estado da Paraíba, fica suspenso, pelo prazo de quinze dias, a partir da zero hora do dia 22 de março de 2020 , passível de prorrogação, nas cidades que tenham casos de Coronavírus (COVID-19) confirmados, e nas suas respectivas regiões metropolitanas, o funcionamento de: (...) II - shoppings, centros e galerias comerciais, bares, restaurantes, casas de festas, casas noturnas, boates e estabelecimentos similares".

21 Decreto municipal n. ${ }^{\circ} 20.625 / 2020$ : "Art. 14. Fica vedado o funcionamento dos shopping centers e centros comerciais, à exceção de farmácias, estabelecimentos de comércio e serviços na área da saúde, posto de atendimento da polícia federal, mercados, supermercados e afins, bancos, terminais de autoatendimento, lotéricas, correios, estacionamentos nele situados, restaurantes, bares e lancherias."

22 A frustração do fim do contrato - total ou parcial - revela-se compatível, ainda, com outras modalidades locatícias, como as locações de bem móveis, regidas pelo Código Civil (arts. 565-578). Tais contratos, no entanto, não parecem ter sido particularmente impactados pela pandemia, razão pela qual não serão objeto de análise mais detida neste artigo. 
a existência, no direito brasileiro, de um dever implícito de renegociar os contratos afetados por patologias, especialmente aquelas de caráter temporário. Trata-se, essencialmente, do dever que incide sobre ambos os contratantes para exigir que, diante de uma alteração superveniente das circunstâncias que gere impacto juridicamente relevante sobre seu contrato, ingressem em renegociação para tentar encontrar uma solução extrajudicial satisfatória a ambos. Tal dever, que já encontra amparo em diversas experiências jurídicas estrangeiras, ${ }^{23}$ pode ser extraído, entre nós, da cláusula geral de boa-fé objetiva (Código Civil, art. 422) (SCHREIBER, 2018, p. 293-297). O dever de renegociar atende, ademais, à máxima da proporcionalidade, na medida em que o ajuizamento de ação judicial de revisão ou resolução do contrato configura o uso de meio excessivo e desproporcional para atingir um fim que as partes poderiam tentar alcançar extrajudicialmente. A própria noção de pretensão resistida - indispensável ao curso de um processo judicial contencioso - não se configura, senão após uma tentativa infrutífera de corrigir extrajudicialmente o curso do contrato impactado.

$O$ dever de renegociar assume especial importância nas relações locatícias afetadas pela pandemia. $O$ caráter temporário do impacto nessas relações recomenda a obtenção de soluções consensuais, reservandose ao Poder Judiciário um papel residual, de ultima ratio para os contratantes. De todos os efeitos que a pandemia produz sobre nossas vidas, talvez um dos mais importantes seja estimular um ambiente de maior solidariedade recíproca, com a compreensão dos sacrifícios mútuos impostos por esse período excepcional, o que torna mais factível o exercício da autocomposição, competindo aos juristas, neste particular, incentivar soluções não litigiosas.

\section{Referências}

ANDRADE JR., Luiz Carlos de. Covid-19: impactos do fechamento do comércio sobre os aluguéis. Conjur, São Paulo, 16 abr. 2020. Disponível em: https://www.conjur.com.br/2020-abr-16/direito-civil-atualcovid-19-impactos-fechamento-comercio-alugueis. Acesso em: 25 jun. 2020.

AZEVEDO, Antonio Junqueira de. Remissão interessada de dívida. Erro sobre o motivo determinante. Análise do negócio jurídico por suas bases subjetiva e objetiva. Frustração do fim do negócio jurídico e consequente enriquecimento sem causa. In: AZEVEDO, Antonio Junqueira de. Novos estudos e pareceres de direito privado. São Paulo: Saraiva, 2009. p. 41-62.

COGO, Rodrigo Barreto. A frustração do fim do contrato: o impacto dos fatos supervenientes sobre o programa contratual. Rio de Janeiro: Renovar, 2012.

FUX, Luiz. A lesão contratual superveniente e a revisão judicial do aluguel. In: TUBENCHLAK, James; BUSTAMANTE, Ricardo (coord.). Livro de estudos jurídicos. Rio de Janeiro: Instituto de Estudos Jurídicos, 1993. v. 7, p. 527-532. Disponível em: http://bdjur.stj.jus.br//dspace/handle/2011/750. Acesso em: 25 jun. 2020.

GALLO, Paolo. Sopravvenienza contrattuale e problemi di gestione del contratto. Milão: Giuffrè, 1992.

KAUFMANN, Erich. Das Wesen des Völkerrechts und di clausula rebus sic stantibus. Tübingen: Mohr, 1911.

KRÜCKMANN, Paul. Clausula rebus sic stantibus, Kriegsklausel, Streikklausel. Archiv für die civilistische Praxis, Tübingen, n. 116, p. 157-161, 1918. Disponível em: https://www.digizeitschriften.de/ dms/toc/?PID=PPN345574613_1918_0116. Acesso em: 25 jun. 2020.

LARENZ, Karl. Base del negocio jurídico y cumplimento de los contratos. Tradução: Carlos Fernandez Rodriguez. Madri: Editorial Revista de Derecho Privado, 1956.

LOCHER, Eugen. Geschäftsgrundlage und Geschäftszweck. Archiv für die civilistische Praxis, Tübingen, n. 121, 1923.

MARINHO, Maria Proença. Frustração do fim do contrato. Indaiatuba: Foco, 2020.

23 Mencionem-se, exemplificativamente, o artigo 1.195 do Code Civil francês (redação conferida pela Ordonnance n. 2016-131, de 10.2.2016); o artigo 1.271 do Código Civil da Romênia, de 2011; os §§ 1.764 a 1.766 do Código Civil da República Tcheca, de 2012; além de, no campo da soft law, o artigo 6.2.3(1) dos Princípios Unidroit relativos aos Contratos Comerciais Internacionais; o item 1:110 da seção III do Draft Common Frame of Reference; e o artigo 6:111 dos Princípios de Direito Contratual Europeu. 
MCELROY, R. G.; WILLIAMS, Glanville. The Coronation Cases - I. Modern Law Review, [S.I.], v. 4, n. 4, p. 241-260, 1941.

OERTMANN, Paul. Die Geschäftsgrundlage - Ein neuer Rechtsbegriff. Leipzig: Scholl, 1921.

PEREIRA, Caio Mário da Silva. Instituições de Direito Civil. Rio de Janeiro: Forense, 2013. v. 3.

SCHREIBER, Anderson. Equilíbrio contratual e dever de renegociar. São Paulo: Saraiva Educação, 2018.

SCHREIBER, Anderson. Manual de direito civil contemporâneo. São Paulo: Saraiva Educação, 2020.

SCHREIBER, Anderson; MANSUR, Rafael. O projeto de lei de regime jurídico emergencial e transitório do covid-19: importância da lei e dez sugestões de alteração. Jus Brasil, Salvador, 30 mar. 2020.

Disponível em: https://andersonschreiber.jusbrasil.com.br/artigos/827105547/o-projeto-de-lei-de-regimejuridico-emergencial-e-transitorio-do-covid-19. Acesso em: 25 jun. 2020.

SCHWARTZ, Andrew. A Standard Clause Analysis of the Frustration Doctrine and the Material Adverse Change Clause. UCLA Law Review, Los Angeles, v. 57, n. 3, p. 789-840, 2010.

SIMÃO, José Fernando. Pandemia e locação: algumas reflexões necessárias após a concessão de liminares pelo Poder Judiciário. Um diálogo necessário com Aline de Miranda Valverde Terra e Fábio Azevedo. Migalhas, [S.I.], 24 abr. 2020. Disponível em: https://www.migalhas.com.br/coluna/migalhascontratuais/325272/pandemia-e-locacao-algumas-reflexoes-necessarias-apos-a-concessao-de-liminarespelo-poder-judiciario-um-dialogo-necessario-com-aline-de-miranda-valverde-terra-e-fabio-azevedo. Acesso em: 25 jun. 2020.

SOUZA, Sylvio Capanema de. Lei do inquilinato comentada. Rio de Janeiro: Forense, 2012.

TEPEDINO, Gustavo; SCHREIBER, Anderson. Fundamentos do Direito Civil. Rio de Janeiro: Forense, 2020. v. 2

WINDSCHEID, Bernhard. Die Lehre des römischen Rechts von der Voraussetzung. Düsseldorf: Buddeus, 1850.

Recebido em: $13 / 08 / 2020$

Aprovado em: 27/09/2020 